\title{
MANUSCRITS MEDIEVALS \\ DEL MATARRANYA (TEROL) \\ I LLURS APORTACIONS AL LÈXIC CATALÀ*
}

\author{
MEDIEVAL MANUSCRIPTS OF MATARRAÑA (TERUEL) \\ AND THEIR CONTRIBUTIONS TO THE CATALAN LEXICON
}

\author{
Javier Giralt Latorre \\ Universitat de Saragossa \\ jgiralt@unizar.es \\ María Teresa Moret Oliver \\ Universitat de Saragossa \\ mmoret@unizar.es
}

Resum: L'estudi de la llengua en què foren escrits els documents antics de la Franja és del tot imprescindible per a contribuir al coneixement de la història de la llengua catalana en aquest territori d'Aragó. Certament, el llenguatge formulari que s'hi troba i l'homogeneïtat escripturària són limitacions d'aquests manuscrits a l'hora d'esbrinar elements realment dialectals, perquè l'espontaneïtat resta restringida a la mínima expressió; de fet, el lector que s’hi apropa comprova que hi ha una scripta coincident amb la d'altres textos de la mateixa època i d'altres zones. Nogensmenys, el seu estudi corrobora que, d'elements marcats diatòpicament, n'hi ha, fins i tot en la sincronia medieval en la qual foren redactats. En aquestes pàgines analitzarem les particularitats lèxiques d'alguns manuscrits del Matarranya dels segles XIV i Xv, clarament occidentals i atestades majoritàriament en documents produïts en l'àrea valenciana o la nord-occidental. També presentarem els aragonesismes aplegats i aquells vocables que no han estat testimoniats enlloc.

Paraules clau: català, diacronia, dialectologia, lèxic, Franja d'Aragó, Matarranya, scripta nord-occidental.

(*) Aquesta recerca s'insereix dins el projecte Aragonés y catalán en el pasado. Diacronía y variación lingüistica en documentación de los siglos XIV y XV ubicada en archivos aragoneses (FFI20I4-52360-P), dirigit pel Dr. Jesús Vázquez Obrador. 
Javier Giralt Latorre \& María Teresa Moret Oliver

Manuscrits medievals del Matarranya (Terol) i llurs aportacions al lèxic català

Abstract: The study of the language in which the ancient documents of la Franja were written is of vital importance to the knowledge of the history of the Catalan language in this region of Aragon. Clearly, the formulaic language that is found in these and the homogeneity of the script are limitations of these manuscripts when it comes to finding truly dialectic elements, given that, in them, spontaneity is limited to a minimum; in fact, readers examining these documents may find that a sort of script exists, coinciding in other texts of the same era and from distinct areas. However, its study corroborates that there are indeed diatopically marked elements, even in the medieval synchrony in which they were written. In these pages, we shall analyze the lexical peculiarities of some manuscripts from Matarraña (Teruel) from the $14^{\text {th }}$ and $15^{\text {th }}$ centuries, clearly Western and mainly attested to in documents produced in the Valencian area or in the North-west. We also present the registered aragonisms and those words that have not been found in any other area.

Key words: Catalan, diachrony, dialectology, lexicon, la Franja of Aragon, Matarraña, Northwestern scripta.

coses es

\section{INTRODUCCIÓ}

La història d'un poble no es pot entendre sense acudir a les seves fonts, produïdes durant segles i conservades en arxius; no hi ha dubte de la necessitat d'apropar-se als escrits perquè són l'única, o si més no, la base més important per al coneixement d'èpoques pretèrites. Si focalitzem l'atenció en un territori com l'Aragó catalanòfon, és clar que una bona part d'aquesta documentació es troba dipositada als arxius municipals, on es custodien bàsicament actes dels antics consells i protocols notarials. Tots aquests manuscrits esdevenen un testimoni fidel de la vida d'un poble, perquè ens aporten valuosa informació demogràfica, econòmica, antropològica, geogràfica, onomàstica, etc. Però també és indiscutible l'atractiu que tots aquests textos tenen per als estudiosos de la llengua catalana, sobretot per a conèixer el passat d'aquesta llengua a la Franja, ja que, en definitiva, és el pilar que sosté la llengua del present.

A més, interessa especialment el vessant diatòpic d'aquests documents, tot $\mathrm{i}$ ser conscients de les restriccions que presenten els textos antics des d'una perspectiva lingüística, perquè l'escriptura no reflecteix la realitat del'expressió oral. Els documents medievals escrits en català es caracteritzen, fins a les acaballes del segle xv, per una gran uniformitat lingüística, per una scripta prou unitària, perquè entre la segona meitat del segle XIII i el començament del segle xv el català havia aconseguit d'establir un model de llengua escrita que progressivament anà ocupant els diversos camps de la cultura i del coneixement, a més de l'àmbit administratiu i jurídic (Moran \& Rabella 
Javier Giralt Latorre \& María Teresa Moret Oliver

20I6: I6I). No s'ha d'oblidar, d'altra banda, que en aquest darrer àmbit la rigidesa en la redacció dels textos afavorí encara més l'homogeneïtat: s'usaven uns determinats esquemes fixos i nombroses fórmules en la redacció, ja que, per la seva mateixa raó de ser, els procediments havien d'estar escrits amb precisió i rigor, evitant possibles interpretacions ambigües; això s'aconsegueix, per exemple, amb la utilització de binomis lèxics (cf. Lagüéns I992b: II28; Moret 2009: 264-265): «puxats dar, vendre, cambiar, obligar, alienar, aver, tenir et poseyr, spletar et fer de aquell a totes vostres pròpries voluntats» (Fondespatla I366). Es podria pensar, doncs, que els documents notarials només serveixen per a investigar les característiques del llenguatge notarial, i no per a conèixer alguna cosa més sobre la llengua oral de la zona en què els textos foren concebuts. Però, res més lluny de la realitat, ja que hom no ha de desdenyar cap de les possibles fonts d'estudi, i menys encara si hom vol accedir a etapes lingüístiques passades, on l'únic recolzament és la documentació conservada (Lagüéns i992a: 24), al costat de l'onomàstica. Com deia Coromines (I997: 277), sota aquella "koiné» escrita s'amagava una llengua viva molt més variada, que en certes ocasions aflora en els manuscrits, per la qual cosa l'anàlisi dels aspectes dialectals esdevé bàsica per a una recerca de caire historicolingüístic. Per tant, la documentació antiga és cabdal per a l'estudi de la variació d'una llengua, i encara més per a la investigació d'aquesta variació des d'una perspectiva diacrònica a la Franja d'Aragó.

La presència de característiques lingüístiques que poden ser considerades dialectals s'adverteix en tots els nivells d'anàlisi, amb més o menys fortuna. Però segurament és el lèxic el component que ofereix una mostra més rica i diversa de constituents marcats diatòpicament, encara que parlar de dialectalismes sembla complicat justament per tractar-se, com hem dit, d'un llenguatge jurídic, amb mots que formen part d'un llenguatge tècnic o d'especialitat, amb una temàtica específica, amb uns usuaris concrets i unes situacions de comunicació determinades, el punt de partida del qual és una llengua més o menys comuna (cf. Moret 2016: 304-305). Tenint en compte aquestes premisses, ens proposem de fer ara una revisió del vocabulari contingut en la documentació escrita en català conservada en alguns municipis del Matarranya (Terol), per tal d'esbrinar quins tipus lèxics poden considerar-se dialectalismes $i$, dins aquest grup, quins estan circumscrits a la zona on foren confegits els documents. Aquests manuscrits pertanyen a dues èpoques diferents:

a) Segle XIv. Pergamins (Per.) referits a diversos municipis del Matarranya (Beseit, Calaceit, Fondespatla, la Fresneda, Massalió, Mont-roig, Queretes, Ràfels, Vall-deroures), I305-I392, amb diversa tipologia documental (cartes, albarans, àpoques, censals, compravendes, concòrdies, concessions, debitoris, dipòsits, requestes, embargaments, atorgaments de tutories). Són 50 pergamins que provenen de diferents fons: Arxiu de

Caplletra 67 (Tardor, 2019), p. 39-64 
Javier Giralt Latorre \& María Teresa Moret Oliver

Manuscrits medievals del Matarranya (Terol) i llurs aportacions al lèxic català

la Corona d'Aragó (I), Arxiu Històric Comarcal del Baix Ebre (6), Arxiu Capitular de Tortosa (I), i els arxius municipals de Fondespatla (23), la Fresneda (I3), Massalió (4) i Calaceit (2). ${ }^{1}$

b) Segle xv. Protocol notarial de Fondespatla (Pro.), I398-I429, amb un total de 97 testaments i codicils (veg. Giralt 2016), conservat a l'arxiu de Fondespatla.

\section{MOTS MARCATS DIATÒPICAMENT}

Comentem a continuació algunes paraules que, des del nostre punt de vista, estan marcades diatòpicament, si més no en algun dels tres sentits següents: ${ }^{2}$ I) perquè, a partir de la procedència de la documentació coneguda, s'albira ja en època antiga una utilització no generalitzada del tipus lèxic en qüestió; 2) perquè algunes formes lèxiques, tot i ser generals en el domini catalanoparlant, presenten variants que foren privatives d'una zona dialectal; i 3) perquè hi ha vocables que, a pesar d'haver gaudit en l'època medieval d'un ús prou estès en l'àmbit lingüístic del català, actualment han esdevingut dialectals per abraçar un espai geogràfic més restringit. ${ }^{3}$

açut (Per_1330); açuts (Per_1330). 'Assut, mur de contenció que atura o desvia l'aigua d'un riu per aprofitar-la en l'agricultura o en la indústria': «que la aygua que sie partida per eguals parts a la açut que en Bertolomeu d'Artigues à feyta o feyta fer en dret de l'ort d'en Domingo Andreu»; «moliners o qualssequer altres persona o persones trencaran l'aygua dels molins o molí de Fontespatlla o çèquies o açuts d'aquell». Prové de l'àrab as-sudd 'obstable, obstrucció'; en un dels testimonis recollits s'observa que és substantiu de gènere femení, com a conseqüència de l'aglutinació de la vocal inicial del mot amb l'article (DECat I, 46ob-46ra). Actualment és paraula pròpia de l'àrea valenciana, de la ribera de l'Ebre i del Matarranya, fins i tot com a femení ( $A L D C \mathrm{IV}$, mapa 765$)$.

alboreda (Per_1379). 'Arbreda': «Item un ort, alboreda, que és ê.l dit terme en la partida del Mas dels Abellés». Variant dissimilada del substantiu arboreda (cf. arbreda),

I. Aquests manuscrits han estat editats per Giralt \& Moret (2018).

2. Com afirma Ferrando (200I: 526), a l'hora de determinar dialectalismes en l'època medieval, «sempre s'hauran de relativitzar les dades, ja que ben sovint s'ha d'entendre el dialectalisme de l'època simplement com a tendència cap a la preferència d'un mot o d'una variant formal en una determinada zona».

3. Cada mot va seguit d'una referència que inclou l'abreviatura del corpus documental, segons s'ha indicat en la introducció, i l'any o anys de datació del testimoniatge. 
Javier Giralt Latorre \& María Teresa Moret Oliver Manuscrits medievals del Matarranya (Terol) i llurs aportacions al lèxic català

que segueix viva a l'àrea de Tortosa i Ribera d'Ebre; segons Coromines (DECat I, 36rb), alboreda es documenta per primera vegada a començaments del segle XV, per la qual cosa el testimoni aplegat als manuscrits del Matarranya permet d'avançar-ne la datació.

almaraxes (Pro_I429). 'Almorratxa, garrafa': "Item almaraxes de vidre e greals de tera». De l'àrab hispànic marráiša, variant de l'àrab mirášša (derivat de l'arrel rašs 'arruixar'). Amb aquest significat apareix en el Libro de la Collida de Barracas (Terol) del segle Xv (Sesma \& Líbano 1982: 78) i almarratxa és anotada per Nebrija \& Busa (I507: I70); avui es conserva marraixa sobretot en valencià meridional (ALDCII, mapa 355). Amb el valor de 'càntir' es concentra a l'àrea del valencià septentrional ( $A L D C$ II, mapa 346; $A L D T$, mapa I07); amb el sentit de 'gerra' sembla perdurar a Lasquarri (Ribagorça), Calaceit (Matarranya) i punts del Maestrat (DECat IV, 484b); i com a 'bota' apareix la variant borratxa a l'Alguer, les Illes Balears, poblacions valencianes septentrionals i el Rosselló ( $A L D C$ II, mapa 353). Cf. també almarregas en documentació aragonesa del segle Xv (Sesma \& Líbano i982: 78).

archevispe (Per_I379); arçevispe (Per_1327); arcevispe (Per_1327); arcebispe (Per_I349). 'Arquebisbe': «en Giamó Agremunt, notari públich de Fontespalla per tota la tera et senyoria del senyor archevispe de Çaragoça»; "a nostre jutge llocal et al senyor arçevispe et al justícia d'Aragó»; "presentà huna carta del senyor arcevispe de Çaragoça»; «Sennyal de mi Pere Solanes, notari públich de Vall-de-roures de la tinença per auturitat del senyor arcebispe de Çaragoza». Prové del ll. ARCHIEPǏsCŏpus i les variants atestades presenten resultats interessants: d'una banda, s'adverteix el manteniment de la segona bilabial sorda etimològica, solució pròpia del català occidental, coincident amb el castellà obispo i l'aragonès bispo/bispe (cf. Fort 1994: 156); d'una altra, el prefix ARCHI-, que conserva habitualment en català el so velar sord per cultisme (arquebisbe), ha seguit l'evolució normal en català del grup -CY- > [s], paral-lelament al comportament del castellà arzobispo i l'aragonès arcevispo, i això tal vegada s'ha produït per influència d'aquest últim; de fet, s'atesta arzevispe de Nápol en un document aragonès de I328 (DECat I, 8IO), com en d'altres del segle Xv (Lleal I997: 42), i àdhuc s'inclou com a veu aragonesa antiquada en el Diccionario de Autoridades $(D A){ }^{4}$

aydar (Per_I372). 'Ajudar, emparar': "et a totes qualssevullen altres cartes que a nós pogesen aydar et a vós noure». Del ll. ADJūTARE, forma sincopada que ja es documenta a l'edat mitjana des de Llull, però que restà limitada posteriorment al

4. Encara que es podria interpretar que el prefix arce-és només una variant gràfica de arche- (cf. Favà 1996: 7I), creiem que s'ha de llegir [arse-] perquè en el mateix manuscrit hi ha la variant arçevispe, amb una $c$ per a la qual no és possible una altra lectura.

Caplletra 67 (Tardor, 2019), p. 39-64 
Javier Giralt Latorre \& María Teresa Moret Oliver

Manuscrits medievals del Matarranya (Terol) i llurs aportacions al lèxic català

català occidental i al mallorquí (cf. DECat I, II7a; Veny 1960: 157-I58; Miralles 1984: 50; Duarte 1985: 45; Casanova 1988: 38; Martí i Castell 2002: 169; Veny \& Massip 2OI3: 202 i 876).

aygües vesants(Per_I379). 'Aiguavessant, vessant d'una muntanya, declivitat d'un terreny per on corren les aigües de la pluja': «que affronte ab terra d'en Bernat Aguira et $a b$ via veynal et $a b$ la serreta aygües vesants et ab terra d'en Guyamó Agramunt». Enregistrem en el manuscrit una variant en plural d'un compost que s'atesta per primera vegada en 1518 en documentació de Castellbò (Lleida); avui és mot estès en català occidental pirinenc i en tot el nord i migjorn del País Valencià (DECat I, 97b). Cf. arag. aguabesante, en un document de Panticosa de 1628 i encara viu en algunes poblacions de la província d'Osca (Vázquez 2004: 192).

bonea (Per_I386). 'Bonesa, qualitat de bo': «que fos merçè et bonea d'ells, per conservar la bona unitat et amistat». Variant de bonesa < ll. BONITIA, amb síncope de la sibilant, usada en la llengua antiga i avui en valencià (Batlle et al. 2016: 157; DCVB).

braçal (Per_1379). 'Braç o ramal de sèquia': «afronte ab heretat d'en Johan Fuster et ab eretat de na Maria, muller d'en Johan Gil, et ab braçal consellal». Mot emprat a l'àrea occidental del català (cf. $A L D C \mathrm{IV}$, mapa 766), que deriva de l'ús de braç amb el sentit de 'séquia o canal de certa entitat', documentat per primera vegada en uns textos lleidatans de II46 i II72 (DECat II, I86b; DCVB). Cf. Fort (1999: 95-96) qui testimonia el mot en documentació de Fraga de I5O2.

cabezes (Pro_I4I4). 'Cap de bestiar': «Item ab açò li lexam per lo dit exovar cinch cabezes de ovelles». Del ll. CAPIัTǏA, amb un significat especialitzat del mot referit al bestiar, als vegetals i al vestit, que té els seus primers testimonis en textos de Muntaner, en documents del Baix Ebre de finals del segle XIII i castellonencs de començaments del segle XIV (DCVB, s.v. cabeça; DECat II, 509b). Referit al bestiar, és mot antiquat en català i només es testimonia avui en parlars de transició de la Franja d'Aragó (cf. Giralt 2005).

capçons (Pro_I429). 'Capçó, eixugamă: «Item quatre capçons de lenz listat». Derivat diminutiu a partir de CAPĨTĬA, usat ja per Llull amb aquest significat (DECat II, 5I2b), que potser s'explica perquè es penjava a un cap o punta (PALDC I, mapa 248); també s'enregistra en el Libro de la Collida de Mont-roig (Matarranya) corresponent al segle Xv (Sesma \& Líbano 1982: 137). Capçó perviu restringit al valencià septentrional; cf. cap̧̧ana, cap̧̧al i cap̧̧ol a la província de Lleida i a Mequinensa (ALDCII, mapa 400). 
Javier Giralt Latorre \& María Teresa Moret Oliver Manuscrits medievals del Matarranya (Terol) i llurs aportacions al lèxic català

corderines (Pro_I429). 'Pell d'anyell o d'ovella': «hun parell de goengues ab son cubertor de corderines". Mot antic, derivat de corder, documentat en textos dels segles XIV i XV, d'ús fonamentalment occidental (DCVB, s.v. corderí; DECat II, 934a; Sesma \& Líbano 1982: 164; Palet \& Romero 1987: 168).

costreta (Per_I38I). 'Constrenyiment, obligació': «aquella matexa costreta et exsecuçió se pusque fer e.s façe per les dites penes». Derivat postverbal de costrènyer atestat en textos de sant Vicent Ferrer (DECat III, 798a); cf. arag. costreyta (Vázquez 20II: 35), constreyta (Borao 1908: 198).

defendre* (Per_I332); deffendre (Per_I379). 'Defensar': «el qual per eles demanàs, responés, defenés en judiçi et fora judiçi et sempre de present en poder del dit justíçia»; «Et que aquelles per evicçió sien per tots tepms obligades et tengudes salvar et deffendre la dita vendiçió per nós a vós feyta de tota mala veu et contrast». Aquest mot procedeix del ll. DEFĚNDĚRE i existí en català fins al segle XVI, com demostren diversos testimonis literaris i no literaris medievals (cf. CICA; Nebrija \& Busa I507: 190; Veny 1960: 16I; Duarte 1985: 92; Farreny 1986: 210 i 2004: 400; Casanova 1988: 78; Bruguera 1999: 6I; Martí i Castell 2002: I7I), encara que, segons Coromines, començà a substituir-se per defensar des dels primers temps de la llengua (cf. DECat III, 4ob-4Ib); no obstant això, com a fidel hereu del verb llatí sembla mantenir-se després en alguns punts de l'àmbit occidental (Veny 1960: I6I; $A L D T$, mapa 487; cf. també Veny \& Massip 2009: 89), incloses algunes zones de la Franja d'Aragó (en concret, la Ribagorça, la Llitera, el Baix Cinca i Maella).

deffenedors (Per_1379). 'Defenedor, defensor': «axí com a leals quirents, autors et deffenedors que som tenguts». És un substantiu derivat de defendre, el qual, tot $\mathrm{i}$ documentar-se en les Vides de Sants rosselloneses del segle XIII, s'usa fonamentalment en textos procedents de l'àmbit lingüístic occidental des de la mateixa època (CICA; Nebrija \& Busa 1507: 19I; Duarte 1985: 93; Casanova 1988: 78; Moret 2010: 290); avui es conserva en valencià ( $D C V B$, s.v. defenedor).

dobla (Per_1360): «per aquell justícia requests la dita pena pagar contradiran los dits tres dies passats aien ésser condempnats o condempnat et encorreguts en pena de la dobla, la qual pena de la dobla si pagar se convendrà s'aia a pagar». Tot i que aquest vocable designà antigament una 'moneda, d'or o de plata, que tenia diferents valors segons les èpoques i regions' (cf. Lleal 1997: I38), en els documents del Matarranya fa referència a una pena que havia de pagar el falsari o enganyós, de la mateixa manera que en els Costums de Tortosa del segle XIII. Es tracta de la substantivació de la forma

Caplletra 67 (Tardor, 2019), p. 39-64 
Javier Giralt Latorre \& María Teresa Moret Oliver

Manuscrits medievals del Matarranya (Terol) i llurs aportacions al lèxic català

femenina de l'adjectiu doble, present des del segle xIII en textos de procedència occidental (DECat III, 192b).

enbaxes (Pro_I403). 'Objectes transportables i utilitaris de tipus divers': «axí aquelles li lex ab tot ço que dintre és, ço és totes e qualssevulles robes, aÿnes, enbaxes, fustes obrades o per obrar, cubs, cubes e totes altres fustes, robes que dintre aquelles són». Mot no contingut en els diccionaris, però sí en el Llibre de Cort de Justícia de Cocentaina (I294-I295), en el Llibre de Cort de Justícia de València (I279-I32I), en altres textos valencians del segle XIV (CICA; Diéguez 200I: 308) i en documentació de les Paüls (Ribagorça) de la segona meitat del segle XVI (Quintana 2007: I78). Potser l'haurem de relacionar amb el baix llatí ambactia 'servei', procedent del gal АмВАсто 'servidor', d'on surten l'italià arcaic ambasia 'servei' i els derivats occitans ambaissada 'encàrrec', 'ambaixada', ambaissador 'ambaixador', l'antic ambaissar 'complir un encàrrec' (cf. DECat I, 271b-272b) i l'occità modern embaisso 'embalatges, sacs, cordatges, etc.' (cf. Coromines I99I: 272), amb el qual enllaçaria el nostre enbaixes amb el sentit que podem deduir pel context en què s'utilitza; el mateix origen té l'antic embaixeries 'encàrrecs, negocis', usat per Eiximenis.

enmenar (Per_I343/1358/1359/1366/1371/1372/1379/1383). 'Esmenar, corregir': "tot vos ho prometem satisfer et enmenar et creure per la vostra simple paraula». Del 1l. ĒMĚNDĀRE, les primeres formes enregistrades en català són emendar i emenar (a començaments del segle XIII), així com esmenar, amb restitució romànica del prefix EX- que es reduí en llatí (DECat III, 6ooa; Duarte 1985: I2I; Martí i Castell 2002: 172). En canvi, la variant enmenar, la més usada en els textos del Matarranya que hem examinat, sembla restringida a d'altres de procedència valenciana de la mateixa època (cf. $D C V B, C I C A$ ). Aquesta forma presenta una modificació de la síl.laba inicial per influx del prefix en-, com succeeix en el castellà enmendar (DCECH II, 634b).

enprestar* (Per_I369/1372/1379/1383). 'Prestar, deixar diners o una altra cosa’: «dos míllia sólidos dinés jaqueses bona moneda, los quals vós per a obs nostres et a neçessitat del dit consell et en nostres nomps propris amigablement enprestàs». Derivat de prestar < ll. PRAESTARE, amb l'afegitó del prefix en-, la primera documentació del qual data de finals del segle XIII en manuscrits occidentals (veg. CICA; Diéguez 200I: 3I2).

enseguir-se (Per_1386). 'Seguir-se, produir-se': «et per esquivar et foragitar tota matèria de dissensions et scàndells et perills que en esdevenidor entre les dites universitats per les coses deiús scrites se porien enseguir». Verb derivat de seguir per aglutinació de en, que formava part de l'estructura seguir-sén 'esdevenir-se' (DECat VII, 746b). Segons la documentació existent, sembla ser una solució preferida en textos 
Javier Giralt Latorre \& María Teresa Moret Oliver Manuscrits medievals del Matarranya (Terol) i llurs aportacions al lèxic català

de procedència occidental, més que no pas oriental, i sobretot valenciana (cf. CICA; Veny 1971: 172; Diéguez 200I: 312). Cf. inseguir en el Llibre de Antiquitats de la Seu de València (Martí Mestre 1994: 308).

exovarar (Pro_I406/I4I4). 'Donar aixovar': «donam-nos licència e falcultat la hu a l'altre que puxe casar e exovarar los dits fills e filles nostres"; "però estan castament e sens marit que puxe casar e exovarar los dits fills e filles meus e seus segons que avem fet a na Bernada, muller d'en Domingo Insa, filla nostra». Forma verbal derivada d'aixovar, procedent de l'àrab aššsuwâr (DECat I, II vocal inicial per influx del so consonàntic palatal. Aquest verb només s'ha atestat en alguns sermons de sant Vicent Ferrer (Schib 1977: 2I), per la qual cosa podem deduir que fou d'ús occidental. En castellà existeix el seu equivalent ajuarar (DLE).

ferreginal (Per_1366); fereginal (Pro_I429); ferreginals (Per_I379). 'Farraginal, lloc on hi ha sembrat farratge; tros de terra situat prop de l'era, i destinat a fer-hi farratge': "cobrar los dits dinés de la dita peyta entre constrets et coreguda et venda del dit ferreginal et ort et de la present carta»; "Afronte lo desús dit fereginal e tera dellà lo regall ab lo fosar e ab via pública e ab tera d'en Pere Bonfill e ab tera sensal de sent Miquel e ab fereginal d'en Pere Oriola»; «affronte ab los ferreginals propés d'en Ramon Castelló et ab via pública». Prové del ll. farragĩnāle i presenta testimonis documentals des del segle XII, amb diferents variants formals, encara que són especialment abundants a l'àrea occidental del català (DECat III, 899a-90oa). Aquesta mateixa solució s'atesta en textos de Massalió de I560 (Fort 2002: I2I); en d'altres de la Ribagorça de mitjan segle xIv hi ha la variant ferreyanal (Moret 20IO: 164). Cf. arag. ferregenal (Fort 1994: 5I) o ferreginal (Navarro 2008a: 109).

fianceria (Per_I368); fiançeria (Per_I32I). 'Acte de donar fermança, seguretat o garantia': «la qual dita fianceria de salvetat yo dit Guiamó Vallès volenterosament faç et atorch»; «la qual fiançeria de salvetad desús dita yo dit en Bertolomeu de Ribol volentés faç et atorc». Sinònim de l'antic fermanceria (Ponsoda, 1996: 273), format a partir de fiança amb el mateix sufix, el qual es documenta en un manuscrit ribagorçà de Sant Esteve del Mall de I3ı6 (Moret 2010: 87), en els llibres de cort de justícia d'Alcoi i Cocentaina del segle XIII (CICA) i en manuscrits de les Paüls de I578 (Quintana 2007: 184); també apareix en el Fuero de Jaca (Molho 1963: 574 i 576) i en textos forals navarresos dels segles XIII i XIV (CORDE).

gronça (Per_I372). 'Gronsa, tremuja del molí d'oliva o de gra': «aprés dell blat que de les dites persones estranyes serà trobat en la gronçà". Veu recollida en textos valencians del segle Xv i en d'altres ribagorçans del segle XVI (cf. DCVB, s.v. gronsa;

Caplletra 67 (Tardor, 2019), p. 39-64 
Javier Giralt Latorre \& María Teresa Moret Oliver

Manuscrits medievals del Matarranya (Terol) i llurs aportacions al lèxic català

Quintana 2007: 186), que es manté en català nord-occidental i valencià, àdhuc amb les variants gruansa i guansa (ALDCV, mapa IO24). És un derivat de gronçar 'columpiar', format sobre una base indoeuropea com ${ }^{*}$ CRONTIARE, pel moviment oscil.latori característic d'aquesta part del molí (veg. DCECH I, 162b i IV, 295b).

llogar (Per_1383); logar (Per_I338); lugar (Per_I372); llogars (Per_I383); logars (Per_1364); loguars (Per_1372); logàs (Per_1375). 'Nucli de població menor que una vila': «hon quer que atrobats seran en fira o fora de fira, en mercat, en herm o en poblat, generalment en tot llogar et singularment et specialment en cadaú»; «establim et hordenam per a tots temps que los jurats et plegadós de les peytes o gites del dit logar de Calaçeyt»; «axí que vós puscau aver plener poder et achtoritat nostra en qualse-

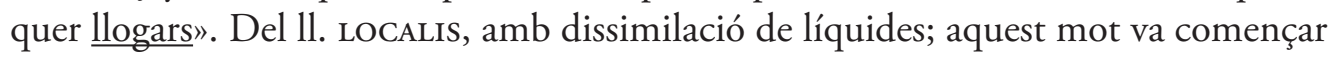
a desaparèixer en català a partir de mitjan segle XIV (veg. Moret \& Tomás 20I4: 155), encara que s'ha mantingut dialectalment a l'àrea del ribagorçà, sobretot en els parlars de transició (cf. DECat V, 235; ALDC III, mapa 692).

menescal (Per_1360). 'Manescal, facultatiu que té per professió curar les malalties de les bèsties': «e.n presència d'en Pere Turró, savi en dret, d'en Pere de Vilalbí, d'en Bernat Aldua, ferrer, et d'en Johan de Ovó, menescal, ciutadans de Tortosa». Prové del fràncic *MARHSKALK 'cavallerís major'; fou solució comuna en català antic (documentada ja des de 1313), però després ha restat restringida a l'àmbit occidental i a l'aragonès (DECat V, 425a; DCVB; Casanova 1988: 138). Cf. Fort (1993: 213), qui testimonia el mot en documentació fragatina de I5OI.

mestura (Pro_I4IO); mestures (Pro_I429). 'Mestall, barreja de cereals': «dues faneques de forment e dues de mestura"; «Item tot lo blat de qualsevulle natura que sie, forment, mestures, ordy, avena e tot ço que sie en les cases e alberch on estam». Mot antic i dialectal, que procedeix del ll. MIXXTURA, encara enregistrat per Coromines al País Valencià i a les valls aragoneses de Benasc, Chistau i Bielsa (DECat V, 625b). ${ }^{5}$

panificar(Per_I37I). 'Disposar una terra perquè produeixi blat': "però si entorn de la terra panificada o en altre qualsevol loch ne havia et aquelles esbrancaran, que de aquelles sien tenguts de lexar lo terç de les rames o més, emperò si en la terra panificada haurà arbre gros de què poguessen exir dos cayrats». Paraula composta de PANIS 'pa' $i$ *FİCCARE 'ficar, clavar', que es documenta en català per primera vegada en un text valencià de $1405 \mathrm{amb}$ el sentit de 'fer pa'; amb el significat atestat en el document del

5. Segons les dades de l’ALDC (IV, mapa 797), només es recollí a Eressué (Vall de Benasc, Osca) i Torremançanes (Alacant). 
Javier Giralt Latorre \& María Teresa Moret Oliver Manuscrits medievals del Matarranya (Terol) i llurs aportacions al lèxic català

Matarranya apareix en algun text català occidental del segle xIv, en Tirant lo Blanch (CICA) i en els Furs de València (Colón \& Garcia 2002: 323), així com en el Libro Lucero de Benasc de 1536 (DECat VI, I55a; DCVB) i en el Diccionario de Autoridades en $\mathrm{I} 737(D A)$.

perayre (Pro_I403). 'Persona que es dedica a l'art de la llana, des del rentat fins al perxat': «Item n'Anthoni Narbona, fill d'en Pere Narbona, que stà a Alcaniz a perayre V sous per amor de Déu». Variant de paraire < ll. parator, per dissimilació de la vocal pretònica, especialment usada en català occidental (DECat VI, 266b; Nebrija \& Busa 1507: 227; Farreny 1986: 216; Fort 1993: 213).

perche (Per_I343). 'Porxo, pòrtic adossat a la façana d'un edifici i limitat amb columnes o pilars de sosteniment': «aplegat al perche de la eglésia de senta Maria del dit loch de la Freyneda». Mot documentat per primera vegada en textos de la Ribagorça i del Matarranya del segle xIV (DECat VI, 728a; Moret 20IO: I44) i també anotat per Nebrija \& Busa (I507: 228) amb el sentit de 'graner', el qual procedeix d'una base * PARRICE, com a variant de PARRICUs 'graner' (> cat. pàrrec), amb evolució mossàrab (DECat VI, 728a), tot i que Veny, sense rebutjar la proposta anterior, assenyala que podria ser un compromís entre els derivats de PORTICU i PERTICA (PALDC 2, mapa I72). Avui s'utilitza, també amb el significat de 'golfa', en català nord-occidental (on hi ha igualment perxi) i pel nord del País Valencià (veg. DECat VI, 728b-730a; ALDC II, mapa 253).

perferta (Per_1386); perfertes (Per_I328). 'Oferiment': «aquells cent florins que la vila de Val-de-roures, Bezeyt, Fondespatla devien al dit honrat en Beringuer de Torrelles per aquella perferta que avien feta al senyor rey». Substantivació del participi de passat de perferir 'oferir espontàniament', variant de proferir < ll. PROFERRE; apareix ja en manuscrits ribagorçans de finals del segle XIII (DECat VI, 779b; Quintana \& Martínez 2007: 100), així com en altres d'occidentals del segle XIV i en el Llibre del fets del rei en Jaume (CICA).

pleytegar* (Per_I383). 'Pledejar, sostenir un procés, contendre judicialment': «ni d'aquest deute ab vós no pleytegarem ni contra la absoluçió del dit deute o partida de aquell». Aquest verb, que deriva del substantiu pleyt, conserva la consonant dental a diferència del que succeeix en cat. pledejar, fr. plaider, oc. plaidar, plaidejar, però en consonància amb l'aragonès pleitear, que fou manllevat després al castellà $(D C E C H$ IV, 578a-b). Haurem d'interpretar que fou una formació pròpia del català occidental a partir del verb aragonès, encara que en altres textos de procedència tortosina $\mathrm{i}$ valenciana de la mateixa època només hi ha pledejar en convivència amb el substantiu

Caplletra 67 (Tardor, 2019), p. 39-64 
Javier Giralt Latorre \& María Teresa Moret Oliver

Manuscrits medievals del Matarranya (Terol) i llurs aportacions al lèxic català

pleit (cf. Colón \& Garcia 2002: 325; Duarte 1985: 125; Ponsoda 1996: 297; Diéguez 200I: 383), fet que persisteix en textos valencians dels segles XVI i XVII (Ponsoda I996: I60). No obstant això, és possible que la forma dialectal pleitejar hagués gaudit d'un ús més ampli, si més no col-loquialment, perquè apareix recollida per Escrig en el seu diccionari valencià-castellà de ${ }^{8} 85 \mathrm{I}\left(D\right.$ Escrig $_{\text {) }}$ i també fou utilitzada en aforismes valencians de mitjan segle XIX (Fages I853: 13) ${ }^{6} \mathrm{i}$ en refranys tortosins de començaments del segle Xx (Bayerri 1979: 506-507), encara que Ponsoda (1996: 160) opina que la pronúncia actual amb diftong en valencià deu ser segurament per influència del castellà pleito.

pobillar (Pro_I4I5). Pobillar edat 'menor de edat': «si aquella morie en pobillar edat». En aquesta locució apareix la variant popular del mot culte pupil.lar (DCVB), la qual s'atesta restringida a textos valencians medievals sota la forma pubillar (CICA; Torró 2009: 87I), amb una variació de la vocal pretònica que resulta constant a l'edat mitjana — i fins l'actualitat - segons els testimonis aplegats de pubill / pobill < ll. Pūpīlluus (DECat VI, 846b-847a).

quartals (Pro_I4Io/I426). 'Quartal, mesura de capacitat de grans, de valor variable': «Item lex nou quartals de forment». Aquest derivat de quart està documentat a les acaballes del segle XIII en el capbreu de la Vall de Ribes (Rasico I990: 375) i al segle xIV en el capbreu de la baronia d'Entença (Palet \& Romero 1987: 199); pel que fa a l'àmbit catalanoparlant actual, resta limitada a la Ribagorça aragonesa i a certs punts del Matarranya (ALDC IV, mapa 852).

rall (Pro_I429). 'Ratllador, raspa de ratllar': «Item hun rall e hun parell de candalobres». Derivat de ralla < ll. RADǓLA 'rascador', atestat en un inventari tarragoní del segle Xv (DECat VII, I26a) i recollit per Nebrija \& Busa (I507: 233) amb el sentit de 'cisell, escarpra'; sembla ser mot propi de l'àmbit occidental (DCVB).

regall(Per_I379, Pro_I399/I40I/I403/I4I0/I4I4/I429); regal(Per_I366). 'Regueró, solc per on passa l'aigua, especialment per a regar': «que affronte ab lo regall de la vila et $a b$ terra et ort d'en Berenguer Gomar et $a b$ via pública et $a b$ ferreginal sensal de sent Salvador»; «axí com afronte de la primera et secunda part ab vies públiques et $\mathrm{ab}$ ort d'en Bernat Andreu et ab lo regal». Derivat de rec, tot i que amb influència de regar pel que fa al significat, present en català occidental $\left(D E C a t\right.$ VII, I65b; DCVB). ${ }^{7}$

6. També s'atesta a finals d'aquest mateix segle, com es pot comprovar en l'explicació del modisme abogat de cuina 'mestre en l'art de donar parer i pleitejar' (Martí Mestre 2006: 2I-22).

7. Amb aquest valor semàntic, l'ALDC (IV, mapa 768) només el testimonia a Fraga. 
Javier Giralt Latorre \& María Teresa Moret Oliver Manuscrits medievals del Matarranya (Terol) i llurs aportacions al lèxic català

sementer (Pro_I429); sementers (Per_I379). 'Sembrat': «aquell dit safrà e safranar li lex a la dita na Catalina ab tot lo sementer que y he en lo dit fereginal; emperò nós dits venedors retenim en nós que no és comprès en la dita vendició los sementers presents, que ara són en les dites heretats, et los safrans». Derivat de sement < ll. SEMENTIS, el primer testimoni del qual es troba en Llull; amb el significat atestat en els nostres manuscrits, sembla conservar-se actualment al Matarranya i nord del País Valencià, tot i que a les Balears és prou viu designant cadascuna de les petites finques que formen una propietat rústica ( $D E C a t$ VII, 769a; DCVB). També apareix en documentació de Fondespatla de 1573 (Fort 2003: 94). Cf. arag. sementero (Fort 1994: 39).

senda (Per_I379). 'Sendera, camí estret per a vianants': «Item unes cases et corral que afronten ab ferreginal d'en Domingo Galí et ab via pública et ab senda”. Procedeix del ll. sĒMĬTA i, encara que sembla tenir un ús ampli en català a l'edat mitjana, la documentació demostra profusió en textos de procedència occidental (CICA; Schib 1977: I35; Casanova 1988: I84); avui s'ha antiquat en català oriental, però no en l'occidental (DECat VII, 784b; cf. ALDC III, mapa 699). Apareix també en manuscrits de Fraga de començaments del segle XVI (Fort 2000: 362).

stal (Pro_I4OI). 'Pleta petita, corralet': "Item lex a Guiamonet Nebot meu lo celler ab les cubes, lo stal vell». Mot que suposa una base sTALL-, tal vegada germànica, documentat per primera vegada en un text de principis del segle XI d'Ovarra (Ribagorça); avui perviu pel Pirineu occidental de parla catalana i aragonesa, així com a la toponímia (DECat III, 734b-735a). Designant un ramat petit en un corralet així, s'atesta en algun punt del tortosí i del valencià septentrional ( $D C V B$, s.v. estall).

thea (Per_1360). 'Teia, fusta resinosa del pi' : "que si alguna perssona del dit loch de Betzeyt o de son terme tallarà ni farà fusta, ni thea, ni carbó o quitrà, ni pega en la devesa de la dita ciutat». Procedeix del ll. TEDA, variant general en català antic fins al segle Xv, inclosa per Nebrija \& Busa (I507: 242) en el seu vocabulari; és conservada actualment en català occidental (cf. DECat VIII, 372b-373b).

torquadores (Pro_I429). 'Drap de netejar atuells de cuina': «Item quatre torquadores listades ab cotó». Mot derivat de torcar 'netejar, eixugar', verb documentat des d'antic i usat modernament en català occidental i mallorquí, el qual prové del 1l. vg. *TORCA 'torcedura' (DECat VIII, 580a; Veny 1960: I23). El substantiu només l'hem trobat atestat en un Cuern de Corpus Christi de Tortosa de I448: "per fer beles VI thovalles, torquadores, torquamans, torquacoltels e thovaloles» (Massip I992: 74). Per tant, bé podria ser un mot propi del tortosí, del qual existeix la variant masculina torcador en valencià $(D C V B)$.

Caplletra 67 (Tardor, 2019), p. 39-64 
usat (Per_1372). 'Atrevit': «establim et ordenam que denguna persona, vey o abitador del loch de Calaceyt o de son terme, no sie tan usat de levar o fer levar denguna natura de blat o blats per moldre o fer moldre en dengun altre moly de fora lo terme de Calaceyt». Variant de l'antic osat, participi del verb osar 'gosar, atrevir-se' < 1l. vg. Ausare. Segons Coromines (DECat IV, 580b-58Ia), en l'àrea de Tortosa, segons es documenta en un text de I34I, sorgí la pronúncia usat, cosa que introduïa la confusió amb el ver usar, ja que es podia entendre ésser usat com 'estar acostumat' (també es testimonia en documents aragonesos del segle xv); això provocà la preferència per gosar ( $\mathrm{amb} g$ - antihiàtica per fonètica sintàctica) per tal d'evitar malentesos. Tot i així, Bruguera (1999: 35) considera que la seva presència en el Llibre del fets del rei en Jaume fa pensar més aviat en un influx aragonès, ja que n'és la forma general en l'època medieval.

vedalers (Per_1360/1386). 'Vedaler, guardià d'un vedat': «sinó los vedalers que ara són o per temps seran assignats a guardar axí los boschs de la dita ciutat com los boschs del dit loch». Variant dissimilada d'un hipotètic vedader, derivat de vedat, que s'usà sobretot a les terres de l'Ebre i nord valencià (DECat IX, 6rb); cf. arag. vedalero (Fort 1994: 224; Navarro 2008a: 261; Borao 1908: 327; Aliaga 2004: 467).

vendable (Per_I358); vendables (Per_I35I). 'Vendible, que es pot vendre': «la qual dita casa fo et és estada levada vendable per la dita vila de Calaceyt»; «aquells crit et levo vendables o a enpeyorament deu dies continuats». Variant de vendible amb modificació vocàlica per influx de venal (DECat IX, IO2b), de la qual només hi ha testimonis antics en textos de Mallorca (DCVB; CICA).

\section{MOTS DE L'ARAGONÈS}

L'examen d'aquests documents del Matarranya també ens ha permès de comprovar la utilització, tot i que escadussera, de paraules aragoneses com a conseqüència del contacte que en època medieval hi hagué en aquest territori entre l'aragonès i el català per haver estat les llengües pròpies dels repobladors que hi arribaren, sense oblidar, a més, la importància que tingueren dins la cancelleria reial de la Corona d'Aragó; ${ }^{8}$ a partir de mitjan segle XV també comença a tenir importància el castellà,

8. Vegeu, en aquest punt, les reflexions que Martines (2002: I57-I6I) planteja al voltant de la importància de l'aragonès en la configuració del valencià; creiem que cal tenir-les ben presents, atesa la continuïtat geogràfica i lingüística que existeix entre el Matarranya i el nord del País Valencià. 
Javier Giralt Latorre \& María Teresa Moret Oliver Manuscrits medievals del Matarranya (Terol) i llurs aportacions al lèxic català

cosa que s'anirà reflectint en la scripta per la incorporació de paraules (o solucions) castellanes. Els vocables que destaquem són els següents:

aldeya (Per_I389). 'Aldea, poblet que no té civilment ni judicialment existència pròpia, sinó que depèn d'un altre poble': «Feyta carta en Cretes, aldeya de Alcaniz». Procedeix de l'àrab dái $i^{c} a$, amb epèntesi antihiàtica, enregistrada en els Privilegis de Catí (Castelló) de I345 i en documents del Matarranya de I339 i 1397 (DECat I, I68; Fort 2008: 338), pràcticament coincident amb la data del nostre pergamí; també en el vocabulari de Nebrija \& Busa (I507: I70). S’atesta igualment en documentació aragonesa del segle XII (Fort I994: 83), per la qual cosa ben bé podria tractar-se d'una variant d'aquesta procedència en els textos redactats en català, tal com ho afirma Gimeno Betí (I997: 88) en el cas d'un altre document castellonenc del segle XIV; a més, encara és recollit per Escrig en el seu diccionari valencià-castellà de I85I (DEscrig). Actualment, amb el sentit de 'llogaret' s'usa aldea en zones del català nord-occidental i el valencià; pel que fa a la variant aldeia, encara es testimonia a Lleida i a la població tarragonina d'Alió ( $A L D C$ III, mapa 693), mentre que ha esdevingut una forma residual en l'aragonès del Sobrarbe $(T L A)$.

camenya (Pro_I429); camenyes (Pro_I429). 'Jaç de brossa': «Item altra camenya $\mathrm{ab}$ tres goengues e hun parell de lançols de lana». Mot aragonès conservat a l'Alt Maestrat $(D C V B)$ i recollit en diversos repertoris lexicogràfics occidentals (Gimeno Betí I998: I48-I49), procedent potser del ll. *CHAMENI, usat per Berceo i freqüent en la documentació aragonesa dels segles xIv i xv (veg. DCECH I, 773a-774a; Sesma \& Líbano 1982: 13I). També és recollit per Moneva en el seu vocabulari (Aliaga 2004: I28) i actualment es conserva en l'aragonès de la Vall de Chistau amb el significat d'aixovar' (TLA).

centeno (Per_1374). 'Sègol': «trenta quafiços de forment et trenta kafizs de centeno». Mot procedent del ll. [HORDEHUM] CENTĒNUM. És pròpiament una paraula castellana, però amb presència en la documentació antiga aragonesa des del II98 (Fort 1994: 58), ${ }^{9}$ per la qual cosa podem pensar que penetrà en els manuscrits en català del Matarranya a través de l'aragonès, de la mateixa manera que en textos valencians dels segles XIV i XV (CICA; Martines 2002: I7I; Luna-Batlle 20II: 74). Avui és pràcticament l'única solució que es coneix a la banda occidental del domini lingüístic, des de Saidí (Osca) fins a Guardamar (Alacant) (ALDC IV, mapa 796; ALDT, mapa 239).

9. En aragonès medieval és freqüent segle, i com a formes actuals tenim ségal, ságal (Martines 2002: 17I).

Caplletra 67 (Tardor, 2019), p. 39-64 
chançelladura (Per_I305); chançeladures(Per_I305). 'Cancel-lació, anul.lació': «et d'aquella on ere la chançelladura féu cuberta a un libre de notes»; «les altres chançeladures que en aquella escriptura en la primera regló són». Derivat de l'antic cancellar 'cancel.lar' < ll. CANCELLARE, el qual no s'enregistra en català, excepte en el diccionari valencià-castellà d'Escrig de I85I com a mot valencià (DEscrig). Fora d'aquest àmbit lingüístic, apareix en castellà dins les Siete Partidas d'Alfons x el Savi sota la forma cançelladura (CORDE), motiu pel qual s'inclou dins el Diccionario de Autoridades de I729 la paraula canceladura 'la raya o rotura con que se borra o cancela un instrumento o escrito’ amb la citació següent: «Otrosi decimos, que si la rotúra o la canceladúra de la carta fuesse en algunos de los lugares sobredichos, non debe ser creída en juício, ni renovada; fueras ende si aquel que la mostrare pudiere probar que por ocasión, o por fuerza, o sin su grado, otro ficiera aquella rotúra o canceladúrà $(D A)$; a partir d'aquí, aquesta veu fou inclosa com a entrada en totes les edicions del diccionari de la Real Academia Española, des de 1780 fins al 200I (MDA; NTLLE). Pel que fa a l'aragonès, l'única informació que tenim sobre el mot s'incorpora en el Vocabulario de Aragón que Juan Moneva lliurà a la Real Academia Española al voltant de 1924 (Aliaga 2004: 7). Segons Moneva, la paraula cancelladura significa 'tachadura' i és antiquada, atès que només es documenta en les actes del procés de corts d'Aragó de 1398 convocades per Martí I a Saragossa, d'on extreu la citació següent: «con la rasura et cancelladura en el séptimo renglón» (Aliaga 2004: 130)..$^{10} \mathrm{Amb}$ aquestes poques dades podem concloure, doncs, que aquest vocable propi del llenguatge jurídic i administratiu fou compartit només per l'aragonès i el castellà, i que el seu ús escadusser en textos escrits en català fou probablement per influència aragonesa.

cuba (Pro_I403/I404/I407); cubes (Pro_I4OI/I403). 'Bota gran de fusta per a tenir-hi vi': «huna cuba de fusta de roure tinent doents quartés poch més o menys»; «axí aquells ensems ab lo cub e ab les cubes e vexells de tenir vy». Paraula procedent del ll. cupA, usada en nuclis de la Baixa Ribagorça, la Llitera i el Matarranya ( $A L D C \mathrm{~V}$, mapa 97I) $;{ }^{11}$ amb el sentit de 'cup' es recull als pobles castellonencs d'Herbers i Castell de Cabres (ALDT, mapa 342). Segons Coromines (DECat II, niosb), tot i que apareix en un manuscrit pallarès de IIoo, es tractaria d'un manlleu recent del castellà. Tanmateix, la data de registre dels exemples en els manuscrits de Fondespatla i, sobretot, el fet que s'atesti en documentació valenciana del segle XIII (Ponsoda 1996: 263), fa

IO. Segons l'edició de les actes del procés duta a terme per Navarro (2008b: 60), la referència que aporta Moneva apareix en el full 88v i no en el 84 .

II. També fou coneguda a Fraga i Gandesa $(D C V B)$. 
pensar que realment es tracta d'un aragonesisme. Cf. Fort (2003: IOO) qui enregistra el mot en textos de Fondespatla del 1570.

esllegir* (Per_I383); eslegir (Pro_I4O2/I4O3/I406/I4Io/I4II/I4I4/I42I/I422/I424/ I426). 'Elegir, escollir': «dos bons hòmens, los quals vós esllegireu et demanareu»; «en lo qual faz e eslegesch marmesós meus és a saber en Pere Quorals e n’Arnau Piquer veyns del dit loch absents»; «en lo qual eslegim marmesós e exsecutors és a saber en Pere Celma notari e en Bernat Aguira veyns del dit loch absents». Variant del verb elegir < ll. ELǏGĚRE, que per hipercorrecció adoptà el prefix es-, tal vegada per analogia amb el sinònim escollir $\mathrm{o}$, fins i tot, per influència de l'aragonès antic esleir (cf. Buesa 1989: I07). Apareix en documentació escrita en català d'Albelda (Osca) de mitjan segle XVI (Giralt 20I2: I92), és recollit igualment per Moneva en el seu vocabulari aragonès de 1924 (Aliaga 2004: 216) i actualment perviu en el català d'algunes zones de la Franja (Giralt 2005) i en aragonès (TLA). Aquesta evolució fonètica popular també s'enregistra en castellà des del segle XIII en la forma esleer, i a finals del segle XV eslegir (CORDE), encara que aviat s'imposà la solució culta elegir (DCECH II, 55Ib).

logartinent (Per_I364); lugartinent (Per_I364); logarstinents (Per_I37I). 'Lloctinent, el segon en autoritat: "yo en Bernat Bertolomeu, logartinent de alcayt en Valde-roures»; "Al hondrado Bernat Bertolomeu, lugartinent de alcayt en Val-de-roures»; «en Bernat Nicolau et Miquel Cristòvol, notari, veyns de la Frayneda, axí com a logarstinents de jurats». Tot i que els substantius habituals en els documents del Matarranya són lloctinent o tinentlloc, d'acord amb les solucions pròpies del català antic $(D C V B)$, també es testimonia logartinent (i variants) possiblement per adaptació de l'aragonès lugartenient (cf. Lagüéns I992a: I75; Navarro 2008a: 250; CORDE); en un plet ribagorçà de I316-I319 es testimonia la forma tinentlugar (Moret 20I0: 82; Moret \& Tomás 20I4: I60), segurament presa de l'aragonès tenientlugar (Lagüéns I992a: 175).

minguar* (Per_1369). 'Minvar, disminuir': «sy alguna cosa en minguarà, que us entreguen en los altres béns nostres obligats a nós en general». Sembla que minguar no és una solució pròpiament catalana, atestada antigament per primera vegada en el Llibre de Cort de Justícia de Cocentaina del segle XIII, potser com a manlleu de l'aragonès antic (Ponsoda I996: 287), com seria el cas del manuscrit del Matarranya. Actualment s'usa minguar i mingua en alguna zona occidental fronterera de l'àmbit lingüístic català (DECat V, 597b; Giralt 2005) i en aragonès (cf. Arnal 2003; TLA).

préstem (Per_I374); enpréstem (Per_I374); enpréstemps(Per_I374). 'Préstec': «en la qual dita procuració volie poder de manllevar et pendre manleuta o manleutes, préstem o enpréstemps, comanda o comandes de pans, de vi o de oli odres»; "que puxau

Caplletra 67 (Tardor, 2019), p. 39-64 
Javier Giralt Latorre \& María Teresa Moret Oliver

Manuscrits medievals del Matarranya (Terol) i llurs aportacions al lèxic català

manllevar, traure et pendre manleuta o manleutes, enpréstem o enpréstemps, comanda o comandes de pans, oli, vi, odres o de qualssevol altres cosses que vós trobar et aver porets et necessàries seran». Heus aquí una variant del cast. préstamo, arag. priéstamo, port. préstimo, i per explicar-la suggereix Corominas (DCECH IV, 647a) que es pot partir del ll. PRAESTITUMM > it. prèstito, cast. préstido, amb un canvi de la terminació per influència del sufix àton preromà -amo, -imo (cf. páramo, légamo). Pel que fa al nostre mot, haurem de pensar, com en el cas del Llibre de Cort de Justícia de Cocentaina (cf. Ponsoda 1996: 300), que s'ha adoptat i adaptat la solució aragonesa — cf. préstam en el diccionari valencià castellà d'Escrig de I85I (DEscrig) —, però mantenint el vocalisme àton etimològic i que li és propi al català préstec. D’altra banda, en els textos del Matarranya, dues de les formes recollides posseeixen un prefix en-segurament per analogia amb el verb antic emprestar 'prestar'; cf. empréstamo en documents castellans i navarresos dels segles XII i XIII, i també en textos de Fernández de Heredia (CORDE). A més, la solució empréstemps ofereix ultracorrecció en la darrera síl.laba, potser perquè l'escrivà relacionà la terminació del mot amb la paraula temps.

tabardo (Pro_I4IO). 'Abric que cobria des del coll fins més avall de la cintura': «hun tabardo vermell». Variant de tabard, d'origen incert, tal vegada germànic, propagada a través del francès antic tabard; en català es documenta la forma llatinitzada tabardum en un manuscrit mallorquí de 1347 (Veny \& Massip 20I3: 45) i ja tabardo en textos de fi de segle xv, un d'ells valencià (DECat IV, 428b) i un altre lleidatà (Farreny 1986: 218), i es probable que aquesta solució fos aragonesa (cf. Sesma \& Líbano 1982: 342 ), més que no pas castellana (cf. $D C V B$ ). En l'àmbit catalanòfon, aquesta forma es conserva a la Franja (Giralt 2005).

valitat (Per_I374). A valitat de 'per a validitat de, per a validesa de': «comanda o comandes de pans, oli, vi, odres o de qualssevol altres cosses que vós trobar et aver porets et necessàries seran a valitat et profit del dit concell de qualssevol persones de qualsevol ley o condició sien». És un calc de la locució llatina ad validitatem, encara que el substantiu resulta valitat per reducció sil-làbica. S'atesta en aragonès medieval la forma validat en 1354 (Castillón I983: 139 i I40), en castellà medieval amb les variants validat (en I4I5 i I4I7) i validad (en I484 i I540) (CORDE; DCECH V, 733b), i també en documentació valenciana del segle XVII (Baixauli 200I: 23I). En el nostre cas, atesa la data de documentació de l'exemple, podem considerar que és un manlleu de l'aragonès. 


\section{MOTS NO ENREGISTRATS}

Han aparegut, així mateix, unes poques veus i variants lèxiques que no han estat localitzades en cap dels repertoris lexicogràfics consultats ni tampoc en els estudis que s'han dut a terme sobre la llengua catalana continguda en textos medievals d'àrees properes o allunyades del Matarranya. Ens referim als següents vocables:

atrehudaments (Pro_I40o). 'Tribut': "puxe fer e atorgar carta o cartes de vendicions, alienacions, cambis, asensaments, atrehudaments e qualssequer altres testaments». Derivat postverbal d'atrehudar 'tributar', solució enregistrada l'any I400 en els mateixos testaments de Fondespatla i també en textos de Jaca del segle xv (Alvar 2000: 204; cf. Borao 1908: 170), variant del català atrahudar, documentat en I309 (DECat VIII, 829a). El substantiu que atestem actua com a sinònim de trehut, però no se'n coneix cap documentació en català ${ }^{12}$ i l'hem de relacionar amb la paraula medieval aragonesa i navarresa treudamiento 'tributació' (Bofarull I871: 294; Yanguas 1987: 238; CORDE). Per tant, atesa la manca d'altres exemples catalans a hores d'ara, podem suposar que la solució navarroaragonesa fou adaptada al català tal com consta en el manuscrit del Matarranya.

consellal (Per_I379); 36; conçelal (Per_I372); consellals (Per_I383). 'Relatiu o pertanyent al consell': «el qual afronte ab heretat d'en Johan Fuster et ab eretat de na Maria, muller d'en Johan Gil, et ab braçal consellal»; «llà hon d'altres vegades és costumat tenir et justar consell per afers consellals». També hi ha un ús adverbial amb el sentit 'de forma col-legiada, corporativa' en el context següent: «tots ensemble et quiscun de nós, singularment et conçelal, per si et per lo tot obligam tots nostres béns et de cada hun de nós». Evidentment, es tracta d'un adjectiu derivat de consell $<$ ll. CONCĬLIUM, amb l'afegitó del sufix -al <-ALE indicador de pertinença, tot i que no n'hi ha testimoni enlloc. Tan sols testimoniem en aragonès l'equivalent concellar en un document de Panticosa de I628, encara que format amb un prefix diferent (Vázquez 2004: 198).

I2. Tan sols en el Llibre dels fets del rei en Jaume apareix trehudament, encara que en el context en què s'insereix sembla ser un adverbi: «e ço que.ls altres no li gosen dir, li diria jo aitan trehudament com a I cavaller»; planteja Bruguera (1999: 44) que s'hauria de relacionar amb trahut 'tribut', tot i no ser corrent la formació d'un adverbi en -ment a partir d'un substantiu, i que significaria 'tributàriament', però emprat amb un sentit figurat de cortesia, és a dir, 'cortesament'. La interpretació de Bruguera, però, no és encertada segons Ferrando (200I: 527) i cal relacionar el mot amb l'adjectiu aragonès trehudo 'atrevit, agosarat', a partir del qual s'explica perfectament la creació de l'adverbi català.

Caplletra 67 (Tardor, 2019), p. 39-64 
enmena (Per_I369, Pro_I403). 'Esmena, correcció, compensació': «et ab satisfació et enmena de tots dans, greuges et mesions»; "Item vull e man que sien tornats a Ramon Castelló XVIII dinés iaqueses, los quals prenguí d'ell d'enmena». Derivat postverbal d'enmenar (veg. supra); cf. emena en textos jurídics del segle XIII (cf. Duarte I985: I2I; Martí i Castell 2002: I72).

enventarizar (Pro_I40o); inventarizar (Pro_I4IO): 'Inventariar': "Emperò vull e man que no li sie ni puxe éser feyt invantari ni enventarizar béns tenguts»; "e que no ly puxe éser feyt inventari negú ni a agreugats de inventarizar aquells per neguna persona». Derivat d'enventari (doc. I295) o inventari (doc. 1376) < ll. INVENTARIUM 'llista de tot allò que s'ha trobat', d'on surt el verb inventariar, atestat ja en I399, afegint-hi el sufix -ar <-ARE, el més usual per a la formació de nous verbs en català (DECat IX, II7a); tanmateix, en els textos de Fondespatla hi ha una forma creada amb el sufix -izar (actualment -itzar) <-IZİARE (Moll 2006: 264), tal vegada per analogia amb nombrosos cultismes verbals constituïts amb aquesta terminació.

frascules (Pro_I4IO). 'Coses de poc valor': «ab totes e qualssevulle aÿnes, robes, frascules de ly e de lana». S'haurà d'interpretar aquest mot com a variant del català frascoles, diminutiu de frasques 'menudalla', del mateix origen que l'italià frasca 'ramatge' i del castellà dialectal frasca 'coses molestes' (d'on surt enfrascarse), però d'etimologia desconeguda, tal vegada preromana indoeuropea (DECat IV, I69a). La forma frascola es documenta en 1382 en un manuscrit de l'arxiu de Montblanc $(D C V B)$, però no hi ha testimoni de frascules, amb un estrany tancament de la vocal tònica del sufix, potser per equivocació de l'escrivà.

\section{FINAL}

Si tenim en compte els condicionants comentats a la introducció, és a dir, el llenguatge formulari que s'hi troba i l'esmentada homogeneïtat escripturària, queden clares les limitacions que plantegen els manuscrits del Matarranya a l'hora d'esbrinar elements realment dialectals, perquè l'espontaneïtat resta restringida a la mínima expressió. El lector que s'hi apropa comprova que hi ha una scripta coincident amb la d'altres textos de la mateixa època, però la nostra anàlisi demostra que, d'elements marcats diatòpicament, n'hi ha, fins i tot en la sincronia medieval en la qual els manuscrits foren redactats, encara que cal assenyalar que aquesta conclusió està avalada per la informació que actualment tenim sobre les paraules estudiades a partir del 
corpus bibliogràfic consultat, la qual cosa no vol dir que en un futur algunes de les afirmacions aquí exposades puguin ser matisades o revisades.

De les dades exposades, podem concloure que les particularitats lèxiques dels manuscrits del Matarranya emprats són clarament occidentals i que, a més, són nombroses les que resten atestades en documents produïts a l'àrea valenciana, juntament amb d'altres aplegades en textos d'origen nord-occidental, tot i que amb un pes específic menor; a més, també hi apareixen alguns elements lèxics privatius de la Franja i, en principi, particulars del català d'Aragó. Tots aquests ingredients, doncs, donen una fesomia als escrits medievals de la Franja d'Aragó que en justifica, amb escreix, la recerca i l'estudi lingüístic.

JaVier Giralt Latorre

Universitat de Saragossa

jgiralt@unizar.es

ORCID 0000-0002-55I8-II23

María Teresa Moret Oliver

Universitat de Saragossa

mmoret@unizar.es

ORCID 0000-0002-2336-6094

\section{REFERÈNCIES BIBLIOGRÀFIQUES}

$A L D C=$ Veny, J. \& L. Pons, dir., Atles Lingüistic del Domini Català, Barcelona, IEC,

7 vol. [En línia: < http://aldc.espais.iec.cat/mapes/>, consulta: 25-07-20I8.]

ALDT = Gimeno Betí, Ll. (1997) Atles Lingüistic de la Diòcesi de Tortosa, Barcelona, IEC.

Aliaga, J. L., ed. (2004) Juan Moneva y Puyol. Vocabulario de Aragón, Saragossa, Xordica/PUZ/IFC.

Alvar, M. (2000) Estudios sobre el dialecto aragonés, II, Saragossa, IFC.

Arnal, M. L. (2003) Diccionario del habla de la Baja Ribagorza occidental (Huesca), Saragossa, IFC / Gara d'Edizions.

Baixauli, I. A. (200I) Els artesans de la València del segle XVII. Capitols dels oficis i collegis, València, Universitat de València.

Batlle, M. et al. (2016) Gramàtica històrica de la llengua catalana, Barcelona, PAM. BAYERRI, E. (I979) Refraner català de la comarca de Tortosa, vol. III, Tortosa, La Gràfica. 
Javier Giralt Latorre \& María Teresa Moret Oliver

Manuscrits medievals del Matarranya (Terol) i llurs aportacions al lèxic català

Bofarull, A. de (187I) Documentos inéditos del Archivo General de la Corona de Aragón. Tomo XXXIX. Rentas de la Antigua Corona de Aragón, Barcelona.

BoraO, J. (1908) Diccionario de voces aragonesas, Saragossa, IHP, za ed.

Bruguera, J. (1999) El vocabulari del Llibre dels fets del rei en Jaume, València/Barcelona, IIFV/PAM.

Buesa, T. (1989) Estudios filológicos aragoneses, Saragossa, Universidad de Zaragoza.

Casanova, E. (1988) El lèxic d'Antoni Canals, València, IFV/PAM.

Castillón, F. (1983) «Los sanjuanistas de Monzón (Huesca) (I319-I35I)», Cuadernos de Historia Jerónimo Zurita, 47-48, p. 139-296.

CiCA = Torruella, J. \& M. Pérez Saldanya \& J. Martines, dirs., Corpus Informatitzat del Català Antic. [En línia: <http://www.cica.cat/index.php>, consulta: 20-03-2017.]

Colón, G. \& A. García (2002) Furs de València, vol. ix, Barcelona, Barcino.

CORDE = Corpus diacrónico del español. [En línia: <http://www.rae.es>, consulta: 20-03-2017.]

Coromines, J. (199i) El parlar de la Vall d'Aran, Barcelona, Curial.

Coromines, J. (1997) Lleures i converses d'un filòleg, Barcelona, Club Editor, sa ed.

$D A=$ Real Academia Española (1729) Diccionario de Autoridades. [En línia: <http:// web.frl.es/DA.html>, consulta: 28-03-2017.]

DCECH = CoRominas, J. \& J. A. PASCUAL (I980-I99I) Diccionario crítico etimológico castellano e hispánico, Madrid, Gredos, 6 vol.

DCVB = Alcover, A. M. \& F. B. Moll Diccionari català-valencià-balear. [En línia: $<$ http://dcvb.iecat.net/default.asp/>, consulta: 20-03-2017.]

DECat = Coromines, J. (1980-200I) Diccionari etimològic i complementari de la llengua catalana, Barcelona, Curial, io vol.

DEscrig = EsCRIG, J. (I85I) Diccionario valenciano-castellano, València.

DiÉGuez, M. A. (200I) El llibre de cort de justícia de València (I279-I32I), València/ Barcelona, IIFV/PAM.

DLE = Real Academia Española, Diccionario de la lengua española. [En línia: <http:// dle.rae.es/>, consulta: 15-06-2019.]

Duarte, C. (1985) El vocabulari jurídic del Llibre de les Costums de Tortosa (ms. 1272), Barcelona, Generalitat de Catalunya.

FAGES, N. (1853) Aforismes rurals, València.

Farreny, M. D. (1986) Processos de crims del segle XV a Lleida: transcripció i estudi lingüistic, Lleida, IEI.

- (2004) La llengua dels processos de crims a la Lleida del segle XVI, Barcelona, IEC. 
FAvÀ, X. (1996) «Estudi lingüístic de textos inèdits en català al Matarranya (s. Xv i XVI)», Anuari de Filologia, xIx, Secció C, núm. 7, p. 63-93.

Ferrando, A. (200I) "Aproximació dialectològica al Llibre delsfets, de Jaume I», Arxiu de Textos Catalans Antics, 20, p. 5II-53I.

FOrT, M. R. (1993) «La lengua catalana en documentación del siglo Xvi de la Franja Oriental de Aragón: unas actas del ayuntamiento de Fraga», dins A. Egido \& T. Buesa (eds.), II Curso sobre Lengua y Literatura en Aragón (Siglos de Oro), Saragossa, IFC, p. 193-225.

- (1994) Léxico romance en documentos medievales aragoneses (siglos XI y XII), Saragossa, Gobierno de Aragón.

- (I999) «Lèxic de l'administració i del món rural en documentació municipal de Fraga (s. Xvi)», Caplletra, 27, p. 87-98.

- (2000) «Elements lèxics i toponímics en un document de Fraga de I50I», Aragón en la Edad Media, i6, p. 355-37I.

- (2002) «El català i l'aragonès, llengües en contacte (edat mitjana i moderna)», Caplletra, 32, p. III-I25.

— (2003) «El català en documentació notarial del segle XVI (Baix Aragó)», dins Actes del Dotzè Col.loqui Internacional de Llengua i Literatura Catalanes, Barcelona, PAM, p. 87-IO5.

- (2008) «Bilingüisme en el Baix Aragó: el català i l'aragonès en un document del segle XIV", Aragón en la Edad Media, 20, p. 335-348.

Gimeno Betí, Ll. (I997): «L'adstrat aragonès en un document castellonenc del segle XIV», dins J. Colomina i Castanyer (ed.), Llengües en contacte als regnes de València i Múrcia (segles XIII-XV), Alacant, Universitat d'Alacant, p. 79-98.

- (1998) De lexicografia valenciana (Estudi del Vocabulari del Maestrat de Joaquim Garcia Girona), València/Barcelona, IIFV/PAM.

Giralt, J. (2005) Lèxic de la Llitera, Lleida, Milenio.

- (20I2) La llengua catalana en documentació notarial del segle XVI d'Albelda (Osca), Albelda, Ajuntament d'Albelda / CELl / DPH.

- (20I3) «Empremtes diatòpiques en textos notarials del segle XVI de Roda d'Isàvena escrits en castellà», Alazet, 25, p. 77-96.

- (2016) «Scripta nord-occidental en manuscrits del Matarranya del segle XV» dins Actes del XVIIè Col-loqui Internacional de Llengua i Literatura Catalanes, en premsa.

Giralt, J. \& Moret, M. T. (2018): "Sie manifesta cosa a tots hòmens». El català del segle XIV en textos notarials del Matarranya (Terol), Saragossa, Prensas Universitarias de la Universidad de Zaragoza. 
Javier Giralt Latorre \& María Teresa Moret Oliver

Manuscrits medievals del Matarranya (Terol) i llurs aportacions al lèxic català

LAGüÉns, V. (1992a) Léxico jurídico en documentos notariales aragoneses de la Edad Media (siglos XIV y XV), Saragossa, Gobierno de Aragón.

- (1992b) «Semántica jurídica: binomios léxicos en la prosa notarial», dins Actas del II Congreso Internacional de Historia de la Lengua Española, vol. I, Madrid, Pabellón de España, p. II2I-II28.

LleAL, C. (1997) Vocabulario de la Cancillería Aragonesa (siglo XV), Saragossa, IFC.

Luna-Batlle, Xavier (2OII) Llibre de plantar vinyes e arbres... (Tractat d'agricultura del segle XV), Barcelona, UB/MCI/PAM.

Massip, F. (I992) «Elements teatrals de la processó del Corpus de Tortosa (segles XIVXVII)", Estudis de llengua i literatura catalanes. XXIX. Miscel.lània Jordi Carbonell, 3, Barcelona, Publicacions de l'Abadia de Montserrat, p. 43-80.

Martí i Castell, J. (2002) Estudi lingüistic dels Usatges de Barcelona, Barcelona, Curial/PAM.

Martí Mestre, J. (1994) El "Libre de Antiquitats» de la Seu de València, vol. II, València/Barcelona, IIFV/PAM.

Martí Mestre, J. (2006) Diccionari del valencià col.loquial (segles XVII, XVIII i XIX), València, PUV.

Martines, J. (2002) «L'aragonès i el lèxic valencià. Una aproximació», Caplletra, 32, p. I57-20I.

$M D A=$ Instituto de Investigación Rafael Lapesa de La Real ACAdemia EspañoLA (2013): Mapa de diccionarios. [En línia: <http://web.frl.es/ntllet>, consulta: 28-03-2017.]

Miralles, J. (1984) Un llibre de cort reial mallorqui del segle XIV, vol. II, Mallorca, IEB/ Moll.

Molmo, M. (1963) El Fuero de Jaca, Pamplona, CSIC.

Moll, F. B. (2006) Gramàtica històrica catalana, València, PUV.

Moran, J. \& J. A. Rabella (20I6) «El naixement de la consciència lingüística en la llengua catalana», dins J. Terrado \& F. Sabaté (eds.), El naixement de la consciència lingüistica a l'Edat Mitjana, Lleida, Pagès Editors, p. I55-170.

Moret, M. T. (2009) «Locucions i expressions codificades en documents notarials aragonesos del segle xIv escrits en català", dins Actes del Catorzè Col.loqui Internacional de Llengua i Literatura Catalanes, II, Barcelona, AILLC/PAM, p. 26I-269.

- (2010) Documentació notarial aragonesa del segle XIV escrita en català. Edició i estudi grafemàtic, Saragossa, tesi doctoral inèdita.

- (2016) «La llengua del Matarraña durante la Edad Media», dins C. Laliena (coord.), Matarranya, gentes y paisajes en la Edad Media, Valderrobres, Comarca del Matarranya / Universidad de Zaragoza / Gobierno de Aragón, p. 296-308. 
Javier Giralt Latorre \& María Teresa Moret Oliver Manuscrits medievals del Matarranya (Terol) i llurs aportacions al lèxic català

Moret, M. T. \& G. Tomás (20I4) El pleito del guiaje ganadero de Ribagorza (I3I6-I3I9). Edición y estudio histórico-lingüistico, Saragossa, IFC.

Navarro, G. (2008a) Cuentas del concejo de Mirambel (I472-I489), Saragossa, IET/ CEMA.

— (2008b) Actas de las Cortes de Zaragoza de 1398-1400, Saragossa, Gobierno de Aragón/ CEMA.

Nebrija, E. A. \& G. Busa (I507) Dicccionario latín-catalán y catalán-latín, Barcelona, Puvill Libros S.A., [ed. facsímil i estudi preliminar de G. Colón \& A. J. Soberanas, 1987].

NTLLE = ReAl ACADEMIa Española, Nuevo Tesoro Lexicográfico de la Lengua Española. [Enlínia: <http://ntlle.rae.es/ntlle/SrvltGUILoginNtlle>, consulta: 28-03-20I7.] PALDC = VenY, J. Petit Atles Lingüistic del Domini Català, Barcelona, IEC, 5 vol. [En línia: < http://aldc.espais.iec.cat/mapes/>, consulta: 25-07-20I8.]

Palet, T. \& M. Romero (1987) Capbreu de la Baronia d'Entença (s. XIV), Tarragona, Diputació de Tarragona.

Ponsoda, J. J. (1996) El català i l'aragonès en els inicis del Regne de València segons el Llibre de Cort de Justícia de Cocentaina (I269-I295), Alcoi, Marfil.

Quintana, A. (2007) «Les llengües de la documentació de l'Arxiu del Consell de les Paüls d'Isàvena de I546 a I667 (II)», Alazet, I9, p. 159-256.

Quintana, A. \& L. MartíneZ (2007) «Scripta ribagorçans del segle XiII», dins Xandra. Estudis aragonesos de llengua i literatura, Calaceit, ASCUMA/IEBC, p. 89-IO4.

Rasico, Ph. (1990) «El Capbreu de la Vall de Ribes. Edició criticofilològica i estudi lingüístic», Butlletí de la Reial Acadèmia de Bones Lletres de Barcelona, 42, p. 34I-378.

ScHib, G (1977) Vocabulari de sant Vicent Ferrer, Barcelona, FSVC.

Sesma, J. A. \& A. Líbano (1982) Léxico del comercio medieval en Aragón (siglo XV), Saragossa, IFC.

Torró, J. (2009) Llibre de la Cort del Justícia de Cocentaina, València, UV/AVL.

$T L A=$ Tresoro d'a Luenga Aragonesa, Gobierno de Aragón/ Diputación Provincial de Huesca. [En línia: <http://diccionario.sipca.es/fabla/faces/index.xhtml>, consulta: 15-03-2017.]

VÁZQUEZ, J. (2004) «Notas sobre aragonesismos atestiguados en un documento notarial tensino de I628 y en una copia posterior», Alazet, I6, p. I8I-246.

- (201I) Ordinaciones y paramientos de la ciudad de Barbastro publicados por D. Mariano de Pano. Aspectos lingüísticos, Barbastro, Ayuntamiento de Barbastro.

VenY, J. (1960) «Paralelismos léxicos en los dialectos catalanes. II», Revista de Filología Española, XLIII, I/2, p. II7-2O2.

Caplletra 67 (Tardor, 2019), p. 39-64 
Veny, J. (I97I) «Regiment de preservació de pestilència» de Jacme d'Agramont (s. XIV), Tarragona, Diputació Provincial de Tarragona.

- (2009) Petit Atles Lingüistic del Domini Català, vol. II, Barcelona, IEC.

Veny, J. \& A. Massip (2009) Scripta eivissenca, Barcelona, IEC.

- (2013) Scripta mallorquina, I, Barcelona, IEC.

YANGUAS, J (I987) «Diccionario de las palabras anticuadas que contienen los documentos existentes en los archivos de Navarra, y de su correspondència con el lenguaje actual», Archivo de Filología Aragonesa, 39, p. 205-24I. [Publicat per primera vegada en I854 per la Imprenta Francisco Erasun de Pamplona.] 